\title{
Incidentally Discovered a Self-Inflicted a Nail in the Brain of Schizophrenia Patient
}

\author{
Seungnam Son 1 , Dong-Ho Kang ${ }^{2,3}$, Byung-Hyo Kim ${ }^{4}$ and Nack-Cheon Choi ${ }^{1,3 凶}$ \\ ${ }^{1}$ Departments of Neurology, ${ }^{2}$ Neurosurgery and ${ }^{3}$ Gyeongsang Institute of Health Science, Gyeongsang National University School of Medicine, \\ Jinju, Korea \\ ${ }^{4}$ Department of Psychiatry, Jinju Seongnam Hospital, Jinju, Korea
}

The self-infliction of foreign bodies into the brain represents rare a clinical phenomenon that has been reported primarily in cases in-
volving accidents and suicide attempts. However, various motivations for self-injurious behaviors as well as suicide attempts have been
reported, especially in patients with psychotic illnesses. A 47-year-old man with a history of schizophrenia presented to our hospital due
to the presence of a nail on his plain skull X-ray. He diagnosed paranoid type of schizophrenia about 17 years earlier, and his psychiatric
symptoms were well controlled by medication. Interestingly, he was not aware of the presence of the nail in his brain and showed no
neurological deficits. In the course of detailed history taking, we discovered that the nail was driven into his brain during a hallucinatory
experience that had occurred more than 10 years earlier. Because we believed that removing the nail from his brain would be more dan-
gerous than maintaining the status quo, the nail was not removed. This is a very rare case of a self-inflicted injury involving inserting a nail
into the brain under the influence of hallucinations. The absence of adverse effects or neurological symptoms/signs related to the pres-
ence of a foreign metallic body in the brain for over 10 years is exceptional.
Psychiatry Investig 2011;8:272-274

Key Words Hallucination, Intracranial self-stabbing, Nail, Penetrating injury, Suicide attempt, Schizophrenia.

\section{INTRODUCTION}

The majority of reports about self-inflicted foreign bodies in the brain involve accidents or suicide attempts. ${ }^{1,2}$ However, patients with psychotic illnesses have reported various motivations for self-injurious behaviors involving the brain such as the removal of evil from the head, ${ }^{3}$ obedience to auditory hallucinations, ${ }^{4}$ and frank suicide attempts. ${ }^{5,6}$ Because in almost all reported cases, patients with self-inflicted foreign bodies in the brain have been aware of their injuries, the intervals between insertion of the foreign body and hospital care have been relatively short. ${ }^{2-8}$ In a few cases, however, the patient was not aware of the injury, and the presence of the foreign body in the brain was detected a few months ${ }^{9}$ or even several years after the original injury, ${ }^{10}$ when it had produced neurological

Received: January 17, 2011 Revised: March 22, 2011

Accepted: March 22, 2011 Available online: July 19, 2011

$\triangle$ Correspondence: Nack-Cheon Choi, MD, PhD

Department of Neurology, Gyeongsang National University School of Medicine, 90 Chiram-dong, Jinju 660-702, Korea

Tel: +82-55-750-8077, Fax: +82-55-755-1709, E-mail: brevis1@naver.com

(a) This is an Open Access article distributed under the terms of the Creative Commons Attribution Non-Commercial License (http://creativecommons.org/licenses/bync/3.0) which permits unrestricted non-commercial use, distribution, and reproduction in any medium, provided the original work is properly cited. signs or symptoms.

We experienced a schizophrenic patient who had coincidentally discovered a self-inflicted long nail in his brain. We learned that the nail had been driven into his brain under the influence of hallucinations experienced more than 10 years earlier; he had not been aware of the presence of the nail in his brain and showed no neurological deficits.

\section{CASE}

A 47-year-old man with a history of schizophrenia was transferred to our hospital due to abnormal X-ray findings. Beginning about 17 years ago, he had suffered from auditory hallucinations of swear words directed at him. A diagnosis of paranoid schizophrenia was made, and he had been a patient in a psychiatric hospital for the past 5 years. His auditory hallucinations were well controlled by medication with risperidone ( $2 \mathrm{mg}$ per day). About one week prior to presentation, he slipped on the floor and complained of intermittent headaches. Plain radiographs showed a long nail penetrating his brain, and he was transferred for further investigation.

On neurological examination, the patient was alert, fully oriented, and had no signs of focal neurological deficits (Figure 1). 
On physical examination, the head of the nail was palpable under the scalp (Figure 2). Computed tomography (CT) revealed the presence of a nail about $6 \mathrm{~cm}$ in length as well as metal artifacts at the center of his head (Figure 3). Detailed historytaking revealed that the patient had had a vivid dream of driv-

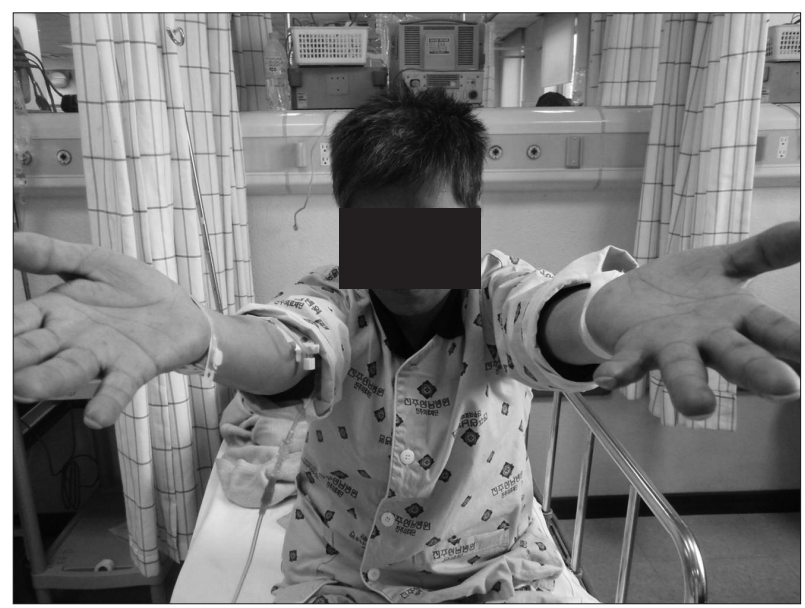

Figure 1. Neurological examination. The patient was alert, fully oriented, and had no signs of focal neurological deficits.

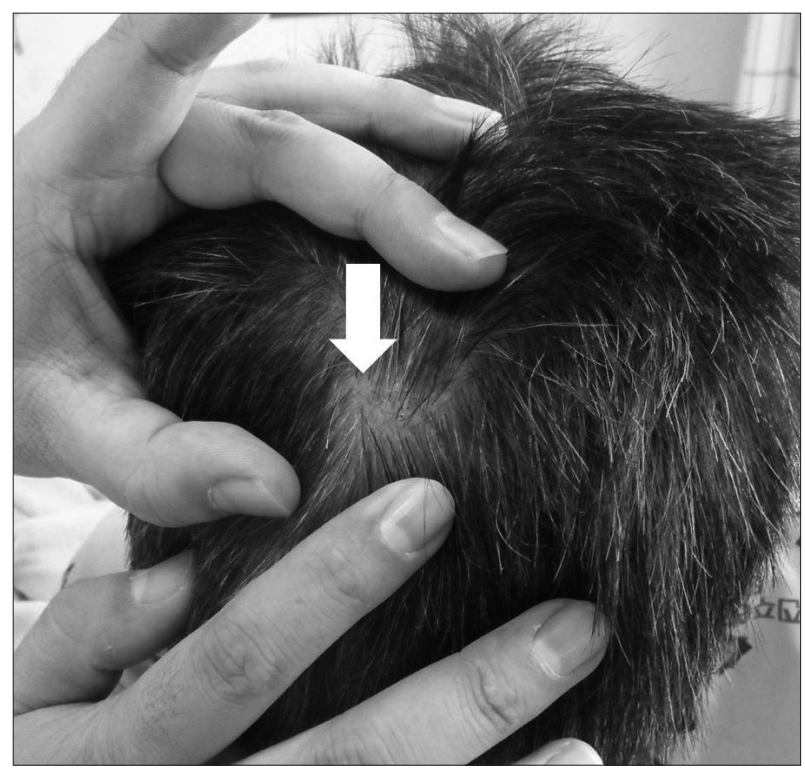

Figure 2. Site of nail insertion (white arrow). The head of the nail was palpable under the scalp. ing a nail into a wall more than 10 years ago, shortly after his auditory hallucinations began. When he awoke the next morning, he reportedly discovered blood flowing from a cut on his head. However, he did not visit a hospital and forgot about the incident. The neurosurgeon suggested that removing the nail from his brain would be more dangerous than keeping it intact, so he was returned to the psychiatric hospital.

\section{DISCUSSION}

This report is very rare case about a self-inflicted foreign body in the brain of a patient with schizophrenia. We think three points are of particular interest in this case. First, to our knowledge, this is the longest time that a self-inflicted foreign body has remained in a brain. Second, both the unawareness of patient and the presence of a nail in his brain per se are unusual. Most remarkable is the absence of adverse effects or neurological symptoms/signs despite the presence of a metallic foreign body in his brain for over 10 years.

Cases of self-stabbing injuries of the brain have been reported in a wide variety of patients with psychotic illnesses, including depression, as well as in patients with personality disorders. ${ }^{1}$ Patients with schizophrenia form the greatest portion of individuals with these injuries. ${ }^{1}$ However, this phenomenon has received little attention from a psychiatric perspective. In many cases, authors have been concerned about the presence of a foreign body in the brain per se and have focused simply on the technical aspects of removing the injurious materials.-5,7-9

Stabbing injuries to the brain constitute emergency situations because they may lead to serious complications such as intracerebral hemorrhaging and later infection. In all previously reported cases, the foreign body in question was removed surgically. ${ }^{1-10}$ However, in the present case, we believed that removing the nail would be more dangerous than keeping its status intact. Brain CT showed that the nail was located almost on the midline and that the tip of the nail reached the junction between body of the corpus callosum and the lateral ventricle. We were not confident about the intactness of the lateral ventricle because of the metallic artifacts around the nail. If the tip of the nail penetrated the roof of the lateral ventricle, in-
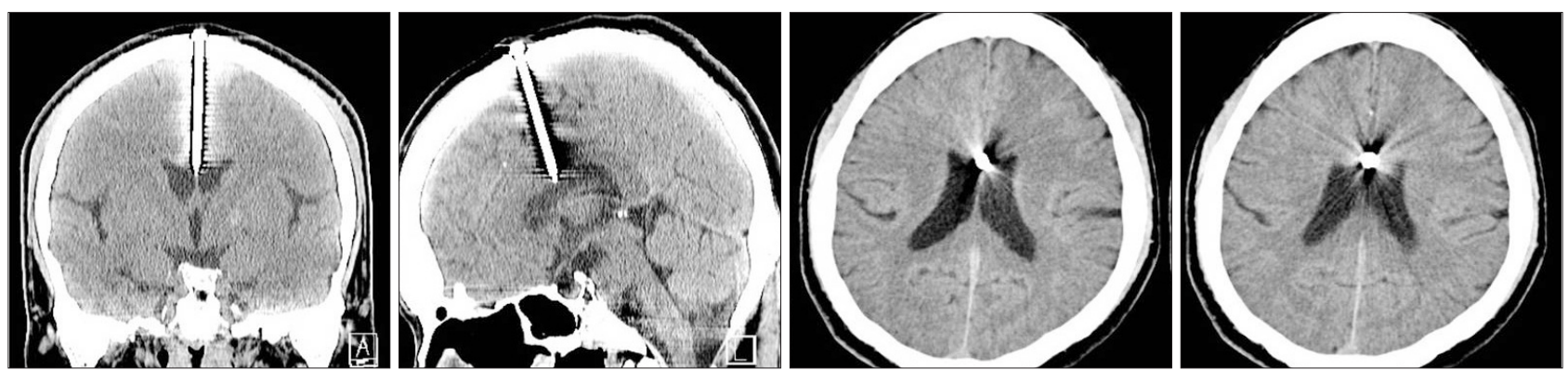

Figure 3. Brain CT scan. Note the presence of a nail about $6 \mathrm{~cm}$ in length in the center of the head with metal artifacts and the intact overlying scalp. 
fection to the central nervous system would be unavoidable. Additionally, the expectable adhesions around the nail caused us to hesitate in removing it. Most decisive in our decision not to remove the nail was that it had not created any neurological symptoms/signs for over 10 years.

We do not know the exact time of nail insertion. The only information available was collected from the patient himself. However, the neurological examination showed that the memory and orientation of the patient were intact, and he provided the same answers during consecutive face-to-face talks with a psychiatrist. We consulted with his attending psychiatrist, who reported that the psychiatric problems of patient were well controlled and that he was ready for discharge. We found no recent traces of scars on his scalp. On these bases, we judged his statements to be credible and concluded that the patient had hallucinated driving a nail into a wall while actually inflicting the injury on himself.

In conclusion, this represents a very rare case of a self-inflicted injury performed under the influence of hallucinations. Further investigations of the psychiatric aspects of intracranial self-stabbing injuries in patients with psychotic illnesses are necessary.

\section{REFERENCES}

1. Large M, Babidge N, Nielssen O. Intracranial Self-Stabbing. Am J Forensic Med Pathol. in press.

2. Kishore K, Sahu S, Bharti P, Dahiya S, Kumar A, Agarwal A. Management of unusual case of self-inflicted penetrating craniocerebral injury by a nail. J Emerg Trauma Shock 2010;3:193-196.

3. Demetriades AK, Papadopoulos MC. Penetrating head injury in planned and repetitive deliberate self-harm. Mayo Clin Proc 2007;82:536.

4. Saint-Martin P, Prat S, Bouyssy M, Sarraj S, O’Byrne P. An unusual death by transcranial stab wound: homicide or suicide? Am J Forensic Med Pathol 2008;29:268-270.

5. Shenoy SN, Raja A. Unusual self-inflicted penetrating craniocerebral injury by a nail. Neurol India 2003;51:411-413.

6. Puri BK, el-Dosoky A, Barrett JS. Self-inflicted intracranial injury. Br J Psychiatry 1994;164:841-842.

7. Vaicys C, Vingan RD, Roth PA, Grigorian A. Splitting of the tentorium leaves by orbital injury. J Trauma 2000;49:166.

8. Strub WM, Weiss KL. Self-inflicted transorbital and intracranial injury from eyeglasses. Emerg Radiol 2003;10:109-111.

9. James G, Blakeley CJ, Hashemi K, Channing K, Duff M. A case of selfinflicted craniocerebral penetrating injury. Emerg Med J 2006;23:e32.

10. Spennato P, Bocchetti A, Mirone G, Savarese L, Squilante D, Rotondo M, et al. Double concentric craniotomy for a craniocerebral penetrating nail. Case report and technical note. Surg Neurol 2005;64:368-371. 